\title{
The Mobile Technology Acceptance Mechanism of Ningbo Electronic Commerce Enterprise under Government Intervention
}

\author{
Songjie Gong \\ Zhejiang Business Technology Institute, Ningbo, 315012, China \\ email:songjie_gong@163.com
}

Keywords: Electronic Commerce; Government Intervention; Acceptance Mechanism

\begin{abstract}
Electronic commerce enterprises adoption and usage of mobile information technologies currently is one of the most fashion trends in information systems research field. In the present research on electronic commerce enterprises, the research of mobile technology acceptance mechanism in Ningbo context is insufficient, lacking the empirical analysis, especially the analysis on adoption influence mechanism under government intervention. The paper researches on the mobile technology acceptance mechanism of Ningbo electronic commerce enterprise under government intervention. It reveals that the behavior science plays a significant role in the evolution of the mobile technology acceptance mechanism and gives an acceptance mechanism under government intervention. It concludes that the mobile technology acceptance mechanism is a useful mechanism which can effectively improve the performance of information technology and support the technology acceptance decision for managers.
\end{abstract}

\section{Introduction}

With the rapid development of networking technology, mobile devices, 4G communication network, more and more enterprises has not satisfied in fixed office and Internet connectivity, and hope to achieve business office applications based on mobile Internet. Mobile commerce technology is to support enterprises to carry out mobile office business applications such as mobile devices, such as mobile devices, mobile Internet, RFID, etc. Ningbo enterprises of electronic commerce because of its typical mobile worker's characteristic, and become the demand of mobile commerce technology is one of the most intense industry, the study on the adoption of e-commerce enterprises in Ningbo mobile commerce technology has attracted much attention. As one kind of enterprise information technology adoption behavior, the information technology adoption research for the mobile commerce technology adoption behavior research, and provided the profound theoretical background.

However, the existing research results in the interpretation of e-commerce enterprises in Ningbo mobile commerce technology adoption intention, still faces great challenges. On the one hand, most of the enterprises are small and medium enterprises, because of their weak strength, in the new technology application process of government intervention in a higher degree of sensitivity. Such as the government financing behavior of mobile commerce technologies, of mobile commerce technologies and their potential application of enterprise training promotion act, will move business technology included in enjoy preferential tax high technology promotion catalog etc., are likely to influence to the e-commerce enterprises in Ningbo on mobile commerce technology adoption intention. On the other hand, due to the e-commerce enterprises in Ningbo New Technology Application of network externality characteristics, making the perceived value is not limited referred to in the existing research the value of technological function, technical and social value in enterprise mobile commerce technology adoption often play an important role.

\section{Government Intervention}

When it comes to government intervention, it is necessary to refer to another term, which is market regulation. In the development of modern market economy, the market is "invisible hand", 
and the government's guide is called "visible hand". In the modern market economy system, the market regulation and government intervention are closely linked, and the important part of each other. Because the market mechanism is completely valid only under the strict hypothesis, and the perfect government intervention is just the same as the "ideal government". That is to say, market regulation and government intervention are not universal, there are inherent defects and failure, failure of the objective possibility, will produce phenomenon of "market failure" and "government failure", as shown in Figure 1

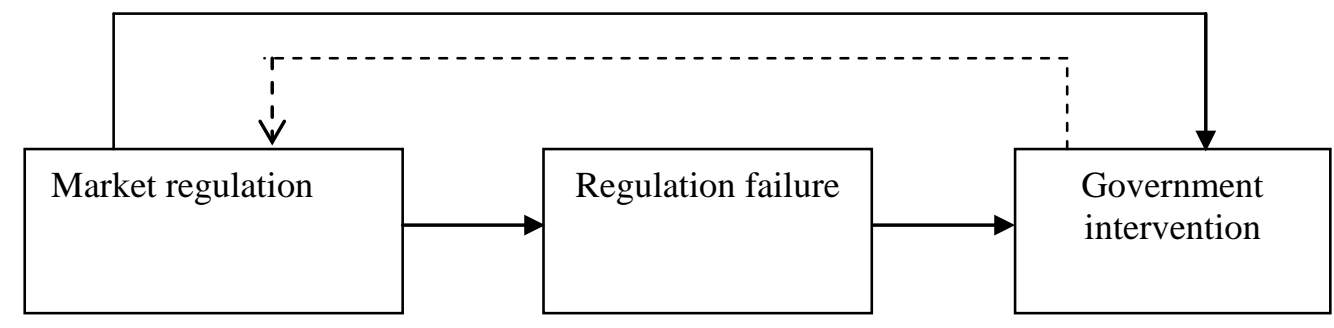

Figure 1 Government intervention and market regulation

In the process of economic development, it is not feasible to rely on market regulation and control of government. The operation of the market in the process will inevitably result in market failures, the private sector has been unable to well solve the problem of resource allocation, this time must be government forces have intervened, macro regulation and control, a series of means and methods to improve the efficiency of resource allocation. This is what we are here to say.

\section{Technology adoption mechanism}

The researchers found that the information system, the model of intentions in social psychology can be used to study the behavior of the individual decision theory based factors. Davies has made the improvement to the other models, specifically for the adoption of information technology research and accept the theoretical model of technology adoption system is put forward. The main purpose of technology adoption mechanism is to provide a basis for looking for effect the external factors on individual beliefs, attitudes and behavior intention. The perceived usefulness and perceived ease of use are the two main beliefs and behavior intention to use technology factors. The perceived usefulness refers to the subjective possibility of future users of a system can increase the work performance, and perceived ease of use refers to the perception of the future users of energy into the use of a technology, as shown in Figure 2.

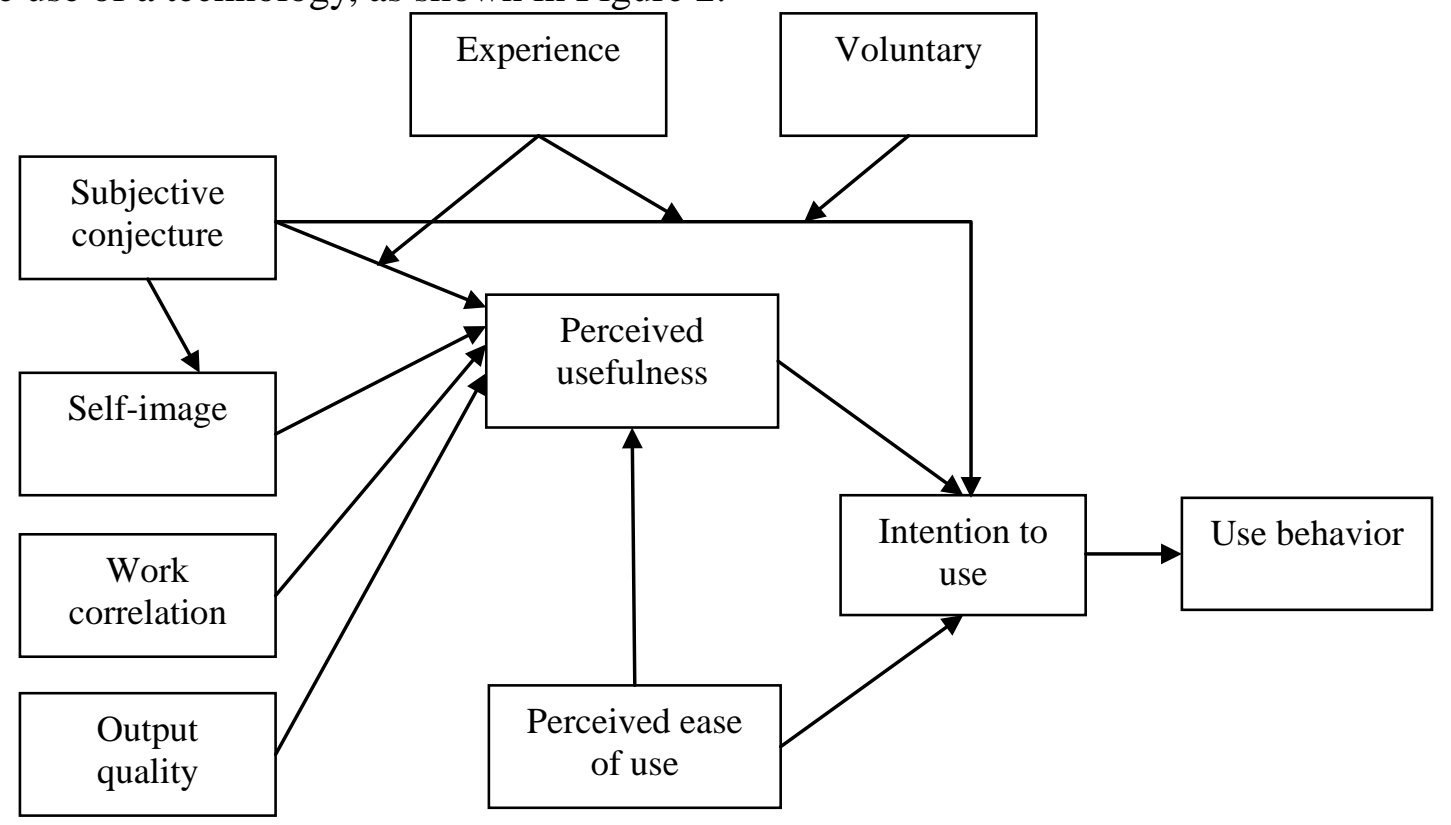

Figure 2 Technology adoption mechanism 
Technology adoption behavior mechanism is considered the use of technology is determined by behavioral intention, and behavior intention by people on the use of behavior attitude and perceived usefulness is determined. That shows the relationship between attitude and behavior intention, other conditions remain unchanged, people usually point to form positive emotion behavior intention to establish the relationship between perceived usefulness. With the intention, because it is the formation of behavior intention towards them that can increase their performance behavior, regardless of whether the behavior can bring the positive or negative emotions. This is confirmed by the research America psychologists in front. Frong think, the performance increase is to obtain various reward means, such as a raise or promotion if people think. This system helps to increase its performance, that is to say the people feel useful, no matter how behavioral attitudes, they usually form the behavior intention. Therefore, attitude only provides a psychological possibility of behavioral intention; perceived usefulness is an important factor is the formation of behavioral intention.

Therefore, the technology adoption mechanism that perceived usefulness and attitude. At the same time, in the external conditions under the same circumstances, one considers the technology more easily, that the man's ability is stronger, the easier it is to form a specific behavior of positive emotions, therefore perceived ease of use and attitude have positive correlation. The model is also proposed, perceived ease of use to increase the perceived performance. People feel the system easy to use, in the use of the process will save a lot of time and energy, make a person more tasks in the same circumstances. To some extent, perceived ease of use caused by increasing perceived performance. Therefore, perceived ease of use has a direct positive impact on perceived usefulness.

\section{Mobile technology adoption mechanism of electronic commerce enterprises under government intervention}

The electronic commerce enterprise mobile technology adoption mechanism under the government intervention attempts to combine government intervention and enterprise behavior factors, as shown in Figure 3.

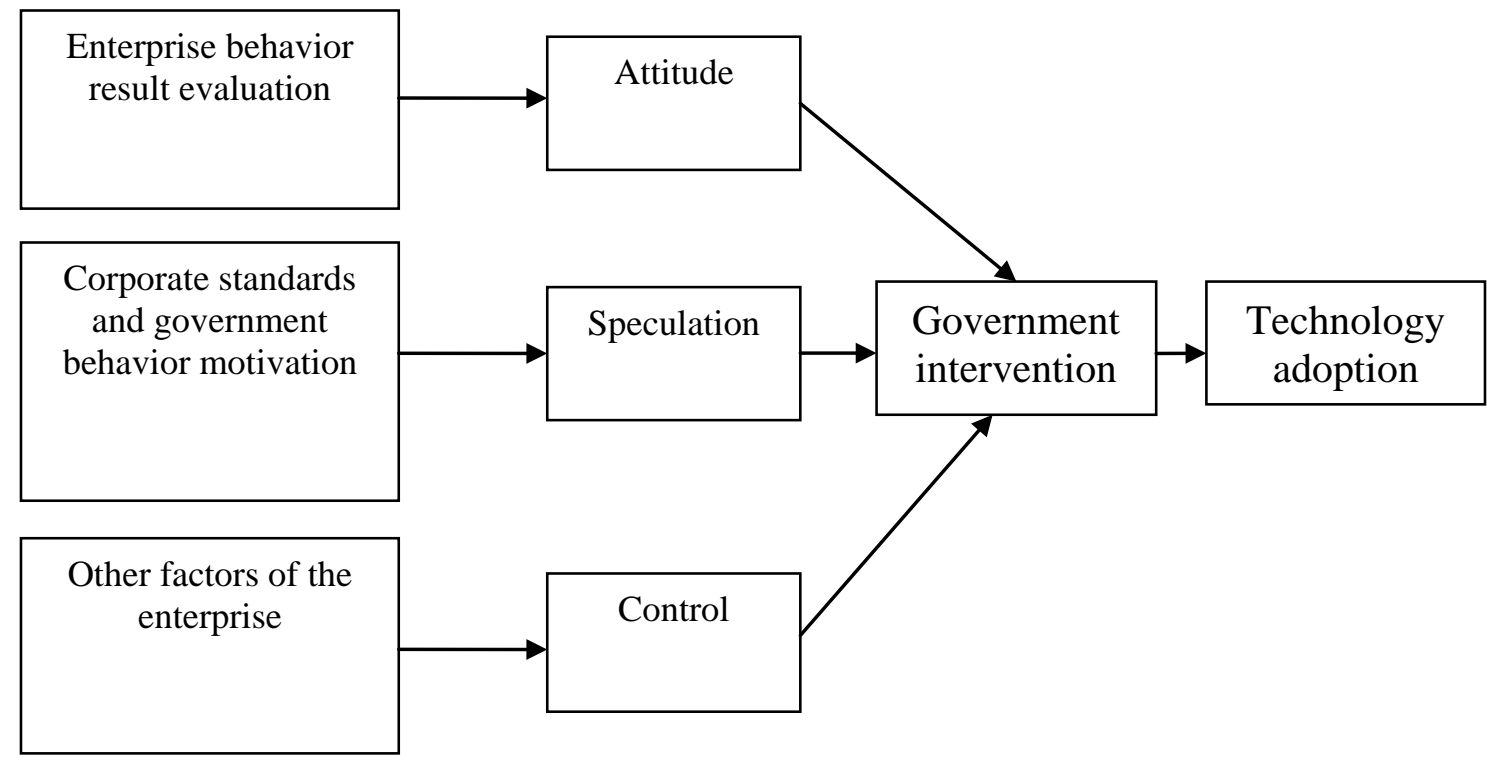

Figure 3 The mobile technology acceptance mechanism of electronic commerce enterprise under government intervention

The mechanism that the behavior of enterprises in a certain extent can by government intervention on intention reasonably inferred. And enterprise's behavior intention is determined by the behavior attitude and corporate standards. Enterprise's behavior intention is enterprises which intend to engage in a particular behavior measure, and the government intervention is to engage in a target behavior held positive impact, it is decided by the important degree of estimation of the 
behavior of the main beliefs of. Standard for business enterprises are enterprises that have an important influence on the perception of the degree.

\section{Conclusion}

In the present research on electronic commerce enterprises, the research of mobile technology acceptance mechanism in Ningbo context is insufficient, lacking the empirical analysis, especially the analysis on adoption influence mechanism under government intervention. This paper researches on the mobile technology acceptance mechanism of Ningbo electronic commerce enterprise under government intervention. It reveals that the behavior science plays a significant role in the evolution of the mobile technology acceptance mechanism and gives an acceptance mechanism under government intervention. It concludes that the mobile technology acceptance mechanism is a useful mechanism which can effectively improve the performance of information technology and support the technology acceptance decision for managers.

\section{Acknowledgement}

This study is sponsored by Ningbo Philosophy and Social Science Planning Projects (Grant No. G15-XK24) and Ningbo Soft Science Research Program (Grant No. 2015A10025).

\section{References}

[1] Gong S, Wang Y. Research on Security Strategy of Electronic Commerce Industry Websites, 2015 International Conference on Advances in Mechanical Engineering and Industrial Informatics. Atlantis Press, 2015.

[2] Gong S. Research on the Generated Path of Electronic Commerce System Based on Innovative High-skilled Technology, 2015 International Industrial Informatics and Computer Engineering Conference. Atlantis Press, 2015.

[3]Wakefield R, Whitten.Mobile computing. A user study on hedonic/utilitarian mobile device usage[J]. European Journal of Information Systems, 2006. 15(3): 292-300

[4]Wu J, Wang S. What drives mobile commerce? An empirical evaluation of the revised technology acceptance model[J]. Information \& Management, 2005. 42(5): 719-729

[5] Songjie Gong, Liping Zeng, The Solution of Safety of Electronic Cash in E-Commerce under Cloud Computing Environment, Advanced Materials Research, Vol. 989, pp: 4314-4317, 2014.

[6] Alain Y L C, Felix T S C, Ooi K B. Predicting consumer decisions to adopt mobile commerce: Cross country empirical examination between China and Malaysia[J]. Decision Support Systems, 2012, 53(1): 34-43

[7] Esther Swilley, Charles F H. The Evolution from E-Commerce to M-Commerce: Pressures, Firm Capabilities and Competitive Advantage in Strategic Decision Making[J]. E-Business Research, 2012, 8(1): 1-16

[8] Archana Sharma, Vineet Kansal. An Analysis of Mobile Transaction Methods and Limitations in Execution of M-Commerce Transaction[J]. International Journal of Computer Applications, 2012, 43(21): $14-19$

[9] Songjie Gong, Research on the Growth Mechanism of High-Skilled System in Computer Science and Technology, Applied Mechanics and Materials, Vol. 513, pp: 2748-2751, 2014.

[10]Hong S J, Tam K Y. Understanding the adoption of multipurpose information appliances: The case of mobile data services[J]. Information Systems Research, 2006, 17(2): 162-179

[11]Venkatesh V, Davis F D. A Theoretical Extension of the Technology Acceptance Model: Four Longitudinal Field Studies[J]. Management Science, 2000, 46(2): 186-204 